\title{
CORRESPONDENCE
}

\section{STANDARDIZATION OF READING TYPES}

\section{To the Editorial Committee of the British Journal of Ophthalmology}

DEAR SIRs-I read with interest and approbation the preliminary memorandum on the Standardization of Reading Types presented by Mr. Frank Law for the consideration of the Council of the Faculty and for comment from the profession at large (British Journal of Ophthalmology, 1951, 35, 765). In a recent issue (British Journal of Ophthalmology, 1952, 36, 689) Mr. Law has set forth the final recommendations of the Council on this subject. I realize therefore that it is too late for effective intervention. There is one point, however, in this second publication which calls for comment as it has an important bearing on our everyday practice and concerns the application of these proposed reading types. When explaining the reduced Snellen type Mr. Law says: "If this type be reduced to $1 / 17$ of its normal size, the letters in the 6/6 line subtend 5 minutes at a distance which very closely approximates to $35 \mathrm{~cm}$. or 14 in., which is an average reading distance." (my italics).

Surely I am not alone in asserting that this is an important misconception: a misconception which I know used to be not uncommon, but which I had ventured to assume would not be perpetuated by being given the authority of the Faculty.

I usually measure the distance between the eyes and the type unconsciously chosen by the patient before any attempt is made to select a passage for reading. Also I have made a practice (and who has not?) of observing the reading and working habits of my fellows in conditions outside the consulting room. Although it might be argued that the majority are in dire need of a new prescription, nevertheless I am satisfied that the average reading distance is certainly not less than $40 \mathrm{~cm}$. or 16 in. A very large proportion prefer 18-22 in., whilst a small minority, mostly women given to sewing, prefer 14 in. Fortunately it is only in those cases where there is no residue of accommodative power when one has to be precise in choosing an exact reading addition, and I would usually choose a plus 2.50 addition for a pair of $6 / 5$ aphakic eyes, sometimes plus 2.25 or plus 2.0 , but only rarely plus 2.75 or plus 3.0 , one of which would have to be chosen if the average reading distance were genuinely 14 in.

In my opinion the conception of a 14-in. average distance can only tend to overprescribing and a no doubt welcome increase in the orthoptist's clientèle.

Furthermore, although the reduced Snellen type is to be used for "an accurate relative assessment for comparative purposes ", the " point " types need not be made unnecessarily valueless in assessment of the vast majority of cases by using the smallest type ( 5 point) at 14 in. The variation in acuity capable of reading this type at this distance is considerable $(6 / 4$ to $6 / 12)$; at 16 in. it would be more selective and at 18 in. still more so. I myself can read the 5-point example (British Journal of Ophthalmology, 1951, 35, 772) with each eye separately, as far away as $65 \mathrm{~cm}$. or nearly $26 \mathrm{in}$. and I make no claim to possessing supra-average eyes.

Yours faithfully,

\section{E. G. RECORDON}

51, Bateman Street, CAMbridge. 